\title{
Award-winning paper in 2018
}

Papers published in Surface Innovations are eligible for awards from the Institution of Civil Engineers. Papers from any of the ICE journals can be nominated for several awards. In addition, each journal has awards dedicated to their specific subject area.

On Friday 4 October 2019, ICE president Andrew Wyllie presented awards to the following paper published in Surface Innovations in 2018. The Editorial Panel nominated their best papers and an awards committee chaired by Robert Armitage allocated the awards.

\section{Surface Innovations Prize}

The Surface Innovations Prize was awarded to Wen et al. (2018).

\section{Abstract}

With the advancement of electrode materials for lithium-ion batteries (LIBs), it has been recognized that their surface/interface structures are essential to their electrochemical performance. Therefore, the engineering of their surface by various coating technologies is the most straightforward and effective strategy to obtain the desirable battery characteristics. Coating the electrode materials' surface to form a specifically designed structure/ composition can effectively improve the stability of the electrode/electrolyte interface, suppress structural transformation, improve the conductivity of the active materials and consequently lead to enhanced cycle stability and rate capability of LIBs. However, due to the restrictions of conventional coating methods, it is still very hard to obtain a conformal and multifunctional coating layer. This paper focuses on recent advances and summarizes the challenges in the development of surface coating technologies for LIBs. Based on these factors, the new concepts of 'ultrathin conformal coating', 'continuous phase coating' and 'multifunctional coating' are proposed and discussed, followed by the authors' rational perspectives on the future development and potential research hot spot in the surface/interface engineering of LIB materials and systems.

\section{REFERENCE}

Wen L, Wang X, Liu GQ et al. (2018) Novel surface coating strategies for better battery materials. Surface Innovations 6(1-2): 13-18, https://doi. org/10.1680/jsuin.17.00056. 